\title{
EXPERIMENTAL SETUP FOR CALIBRATING FORCE TRANSDUCERS
}

\author{
Ciprian Ion Rizescu ${ }^{1}$, Vlad Cozianu ${ }^{2}$, Dana Rizescu ${ }^{1}$ \\ ${ }^{1}$ University POLITEHNICA of Bucharest, Department of Mechatronics and Precision Mechanics \\ 2SAP ROMANIA \\ E-mails: ciprian.rizescu@upb.ro,vlad.cozianu@gmail.com,dana.rizescu@upb.ro
}

\begin{abstract}
The paper aims to design and develop force transducers for industrial environments to cover different values (ranges) of the measuring force. The calibration of the leaf springs was performed using two experimental methods. The first solution entitled (A) was to apply to the springs a force with a number of different calibrated weights. Based on the IMADA ZP500N and ZP5N force transducers and the "ZP Recorder" software application, the second calibration solution entitled (B), was developed by authors. The paper briefly presents the steps taken into account to obtain the force transducers. Processing of the leaf springs, cleaning the surfaces where the strain gauges are to be glued, protecting the strain gauges and finally gluing the terminals of strain gauges for connection to the Catman interface are presented. Calibration of force transducers was performed for different shapes of lamellar springs: rectangular, triangular, trapezoidal. The experimental results for each force transducer were processed using Matlab environment. The best behavior in terms of the characteristics of the transducers is the triangular lamellar spring transducer. Two materials were considered for the lamellar springs: steel and bronze. Depending on the force field to be measured, one material or another is chosen. An important requirement for the operation of these transducers is not to exceed the range of forces for which it was designed.
\end{abstract}

Keywords: Leaf Springs, Lamellar Springs, Force Transducers, Strain Gauges.

\section{Introduction}

The paper aims to design and execute force transducers for industrial environments to cover different values of the measuring force.

The transducers consist of simple and straight lamellar springs (leaf springs) of different shapes: rectangular, triangular and trapezoidal. The control equipment of the transducers based on leaf springs consist of two or four strain gauges connected in the Wheatstone bridge circuit: half or full. A force transducer consists of: the spring blade on which are attached two or four strain gauges, the signal acquisition and transformation system (Spider + PC). An important problem in the manufacture of these transducers is the calibration of the built transducers which must then operate in the industrial environment [1].

In the case of calibration of transducers with weights (calibrated masses), it is necessary to calculate the theoretical deflection at the free end of the spring. For each type of lamellar spring, a loading range corresponding to maintaining a linear characteristic was established. In this way, the characteristic of each transducer can be drawn, which will be used in the experimental determinations.

In the following will be presented the lamellar springs used as well as the number of strain gauges that were glued on them, corresponding to the connection mode on the Wheatstone bridge: half bridge or full bridge. In figure 1 is presented the rectangular shape leaf spring with 2 strain gauges.

[mm]

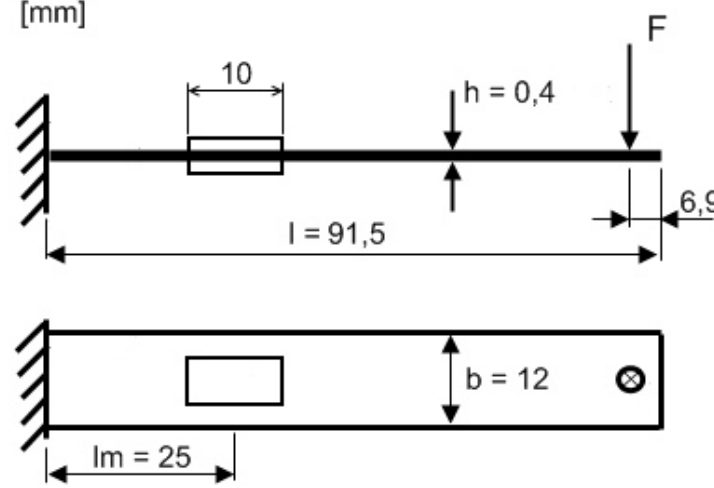

Figure 1: Rectangular leaf spring with 2 s.g.

The strain gauges are glued on both faces of the leaf spring. In this case there was used the half bridge circuit. The next step was to consider the same rectangular shape of the leaf spring but it was equipped with four strain gauges. In this case the full bridge circuit was considered. The width of the leaf spring is increased, in order to glue two strain gauge on each face of the spring. The rectangular shape leaf spring equipped with four strain gauges is presented in figure 2. 


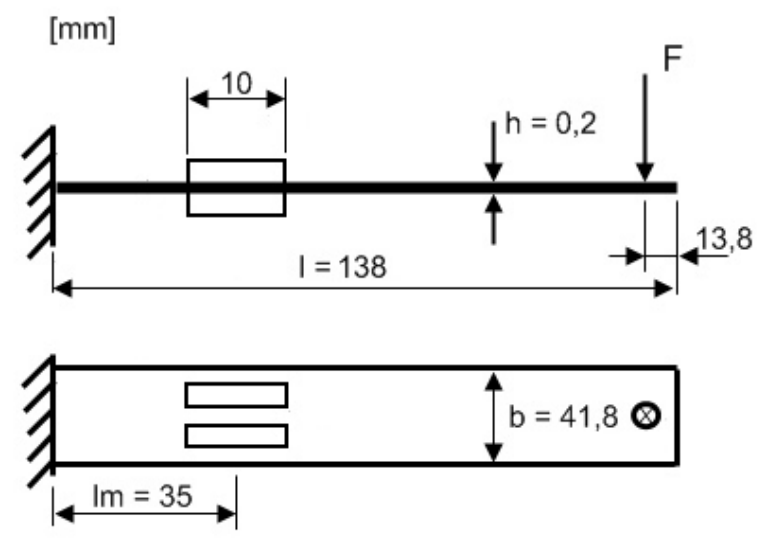

Figure 2: Rectangular leaf spring with 4 s.g.

In figure 3 is presented the triangular leaf spring with four strain gauges and in figure 4 is presented the trapezoidal leaf spring with four strain gauges.
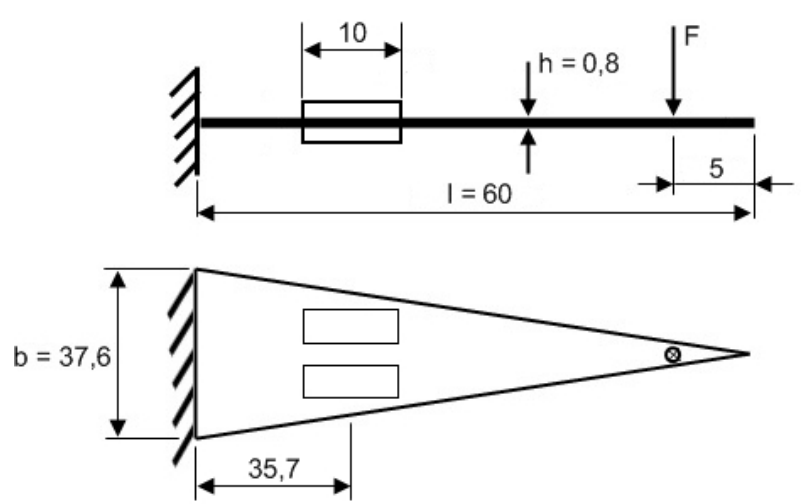

Figure 3: Triangular leaf spring with 4 s.g.

[mm]
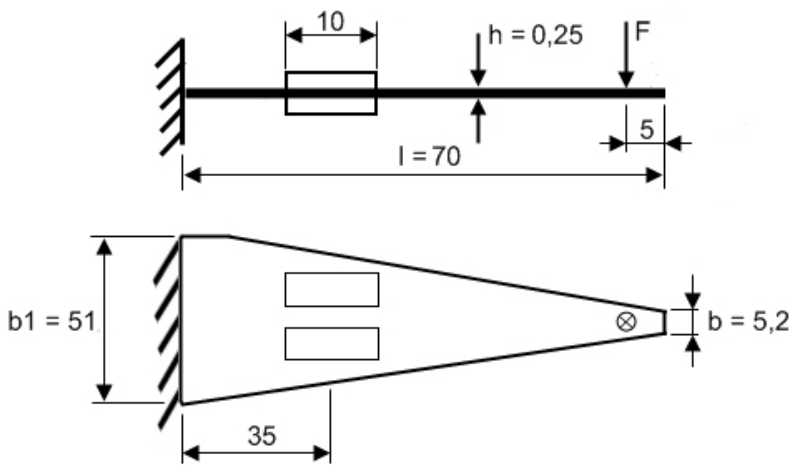

Figure 4: Trapezoidal leaf spring with 4 s.g.

For the rectangular leaf spring, the deflection at the free end of the spring is calculated with the relation $[2,3]$ :

$$
f=\frac{F \cdot l^{a}}{3 \cdot E \cdot I_{z}}
$$

where $\mathrm{f}$ is the spring deflection, $\mathrm{F}$ the operating force, $\mathrm{l}$ - leaf spring length, E - elasticity modulus and $I_{z}$ the inertia moment of cross section.
Regarding the triangular shape of the spring, the deflection at the free end of the spring is calculated with the relation:

$$
f=\frac{F \cdot 1^{3}}{2 \cdot E \cdot U_{z}}
$$

The bending stresses that appear in the area of the strain gauges are calculated with the relations:

$$
\sigma_{i}=\frac{F \cdot x}{W_{z}}
$$

for rectangular leaf spring, where $\mathrm{x}$ is the distance between embedment. section and the strain gauge, $\mathrm{W}_{\mathrm{z}}$ is the strength modulus of the cross section. For triangular and trapezoidal shapes of the springs the relation is :

$$
\sigma_{i}=\frac{F \sqrt{ }}{W_{z}}
$$

where $\mathrm{W}_{\mathrm{z}}$ is computed with:

$$
W_{z}=\frac{b-h^{2}}{6}
$$

where $b$ is the width of the lamellar spring and $h$ is the thickness of the spring.

\section{Experimental setup}

The calibration of the leaf springs was performed by two experimental methods. The first solution entitled (A) was to apply to the springs a force with a number of different weights, from $10 \mathrm{~g}$ to $140 \mathrm{~g}$. For each weight, a value corresponding to the deformation of the strain gauges $(\mu \mathrm{m} / \mathrm{m})$ was recorded by means of Spider and the "Catman-EASY" software application. With help of the IMADA ZP500N and ZP5N force transducers and the "ZP Recorder" software application, the second calibration solution entitled (B) was developed [4]. This calibration consisted in programming the IMADA force transducer, in order to apply forces between $0.1 \mathrm{~N}$ and $1.4 \mathrm{~N}$ on the lamellar springs, and the result can be read with the help of the Spider acquisition system and the software application "Catman-EASY .

The HBM strain gauge range consists of the $\mathrm{Y}, \mathrm{C}$, M, G series and special strain gauges [5]. There are different type series within each strain gauge series. Many specifications are identical for one strain gauge series. The authors used strain gauge from HBM : G series, type LG11-6/350. Some features of G series:

- G series strain gauges are optimal for the manufacture of transducers, with a nominal electrical resistance of $120 \Omega$ and $350 \Omega$; are used by gluing on different materials with a special adhesive 
- These are located on a fiberglass support reinforced with a phenol resin, they have a single measuring grid from Constantan.

- Type LG11-6 / 350 is used for aluminum transducers with a measuring grid length of $6 \mathrm{~mm}$ and a nominal electrical resistance of $350 \Omega[6,7,8]$.

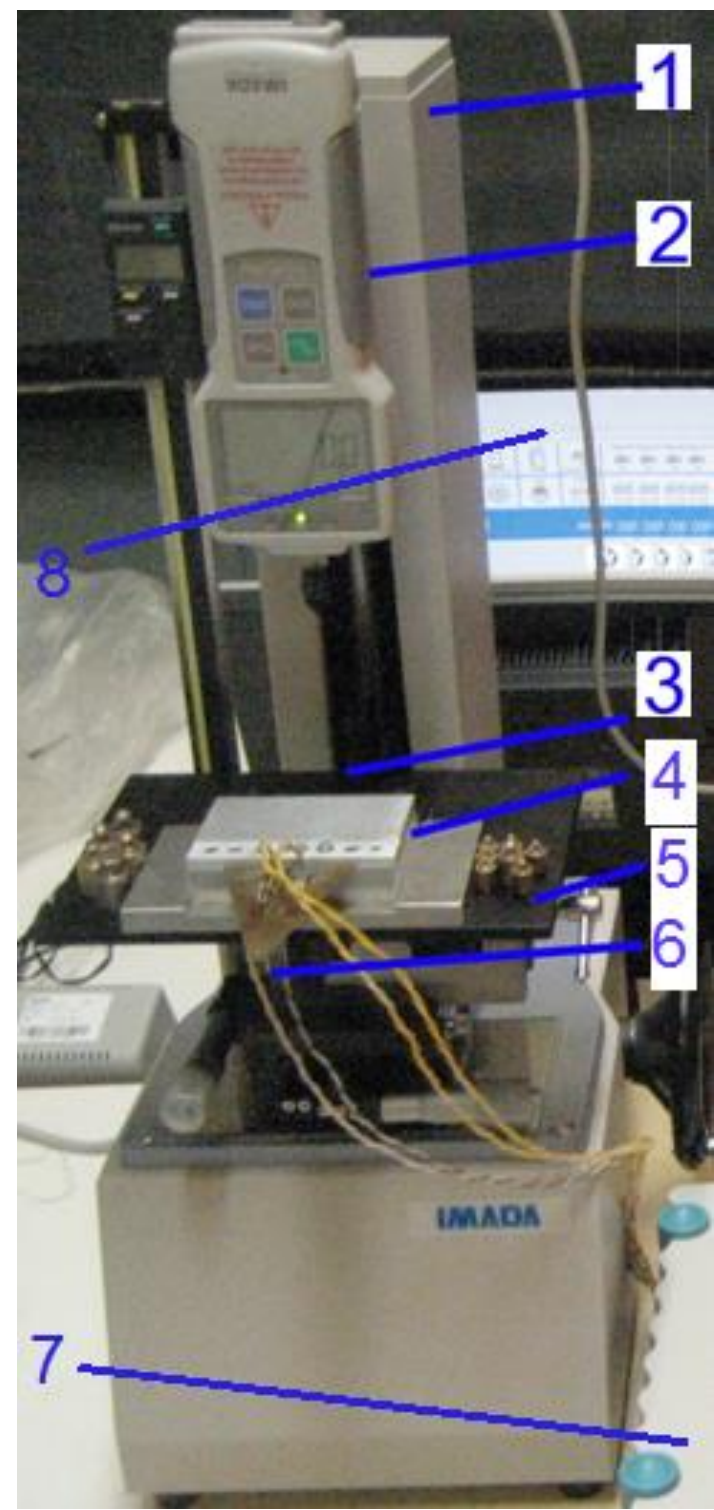

Figure 4: Experimental setup.

The experimental setup comprising both solutions (A) and (B) is presented in figure 5. Mainly, the experimental setup for calibrating the force transducers consists of the following components:

1. Hans Schmidt vertical test stand HV 500;

2. Imada ZP500N force transducer;

3. XY table attached to the guide system;

4. Lamellar spring support stand;

5. Calibrated weights (10 ... 140 [g]);

6. Trapezoidal lamellar spring equipped with strain gauges connected to 7;

7. Spider signal acquisition and transformation system;

8. Notebook with "Catman-EASY" software.
In figure 6 is figured solution A for experimental setup. The components labeled in figure 6: 1.Calibrated masses (grams),2. Lamellar spring, 3. HBM Hottinger $350 \Omega$ strain gauges, lamellar spring support, 5. Spider 8 - acquisition system + "Catman-Easy-AP" software application, 6. PC - with the "Catman-Easy-AP" application for signal processing.

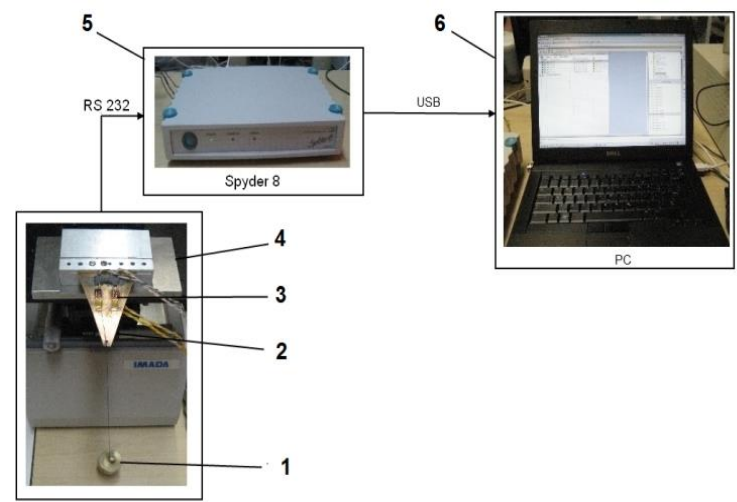

Figure 6: Experimental setup: solution A

In figure 7 is figured solution A for experimental setup. The components labeled in figure 7: 1. Hans Schmidt vertical test stand HV 500N, 2. leaf spring support, 3. Lamellar spring to be tested (future force transducer), 4. Imada ZP-500N / 5N power transducer, 5. Spider 8 acquisition system + "Catman-Easy-AP" software application, 6.PC - with "Catman-Easy-AP" application.

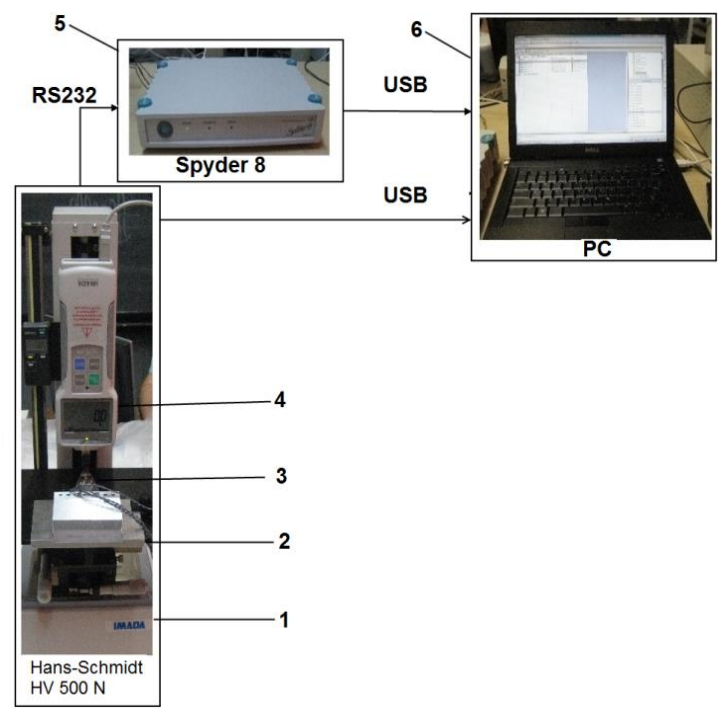

Figure 7: Experimental setup: solution B

The calibration of the leaf springs was performed by two experimental methods. The first solution entitled (A) was to apply to the springs a force with a number of different weights, from $10 \mathrm{~g}$ to $140 \mathrm{~g}$, (figure 6). For each weight, a value corresponding to the deformation of the strain gauges $(\mu \mathrm{m} / \mathrm{m})$ was recorded by means of Spider and the "Catman-EASY" software application. 
With help of the IMADA ZP500N and ZP5N force transducers and the "ZP Recorder" software application, the second calibration solution entitled (B) was developed. This calibration consisted in programming the IMADA force transducer, in order to apply forces between $0.1 \mathrm{~N}$ and $1.4 \mathrm{~N}$ on the lamellar springs, and the result can be read with the help of the Spider acquisition system and the software application "Catman-EASY, (figure 7) . The output signal of the tension / compression of the lamellar spring to be checked is acquired and transformed using the Spider system (5) .

To initialize a measurement using Spider and the "Catman-EASY" application, one can need to perform a few steps that are influenced by the number of strain gauges pasted on the transducer and their characteristics:

1) choosing the type of sensor;

2 ) if the strain gauges are (2 or 4 ) in full or half bridge it will be chosen accordingly as is shown in figure 8;

3) associate the type of sensor chosen in point 2) to the corresponding channel where the force transducer with 2 or 4 strain gauges is connected;

4) choose the type of data visualization (figure 9); data can be downloaded simultaneously from all 8 channels (see figure 10), the application can finally generate a file with the extension .XLS (EXCEL) containing the data from the 8 channels - figure 11 .

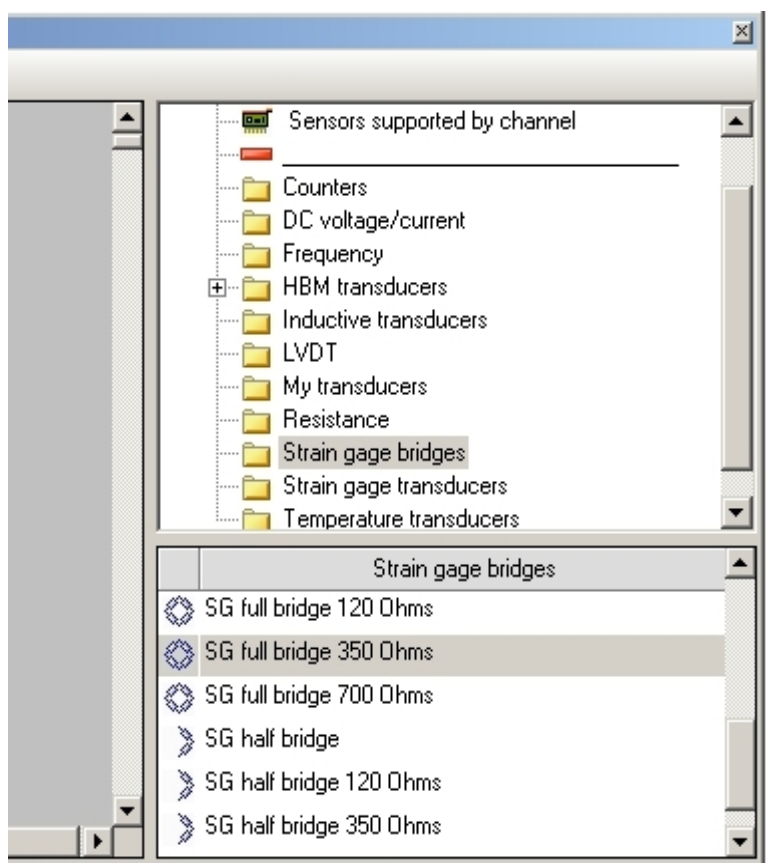

Figure 8: Selecting the type of bridge

Some of the advantages of the Catman - EASY application
- obtaining reading results quickly due to the modern and intuitive interface;

- library of experimental stress analyzes;

- graphical data analysis with the possibility of exporting data for the measurement curve (e.g. WORD);

- possibility to export data in common formats (Word, Excel, ASCII);

- optional extension modules for specific activities (mathematical analysis).

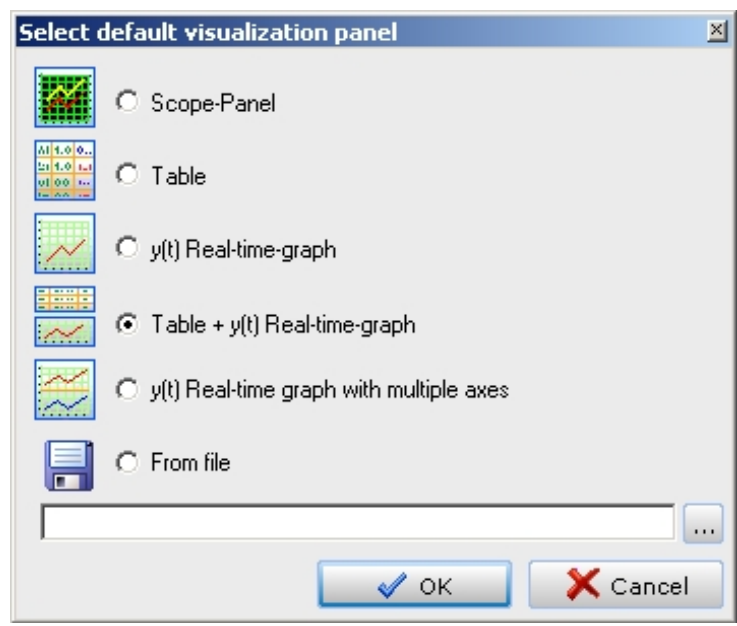

Figure 9: Selecting data visualization type
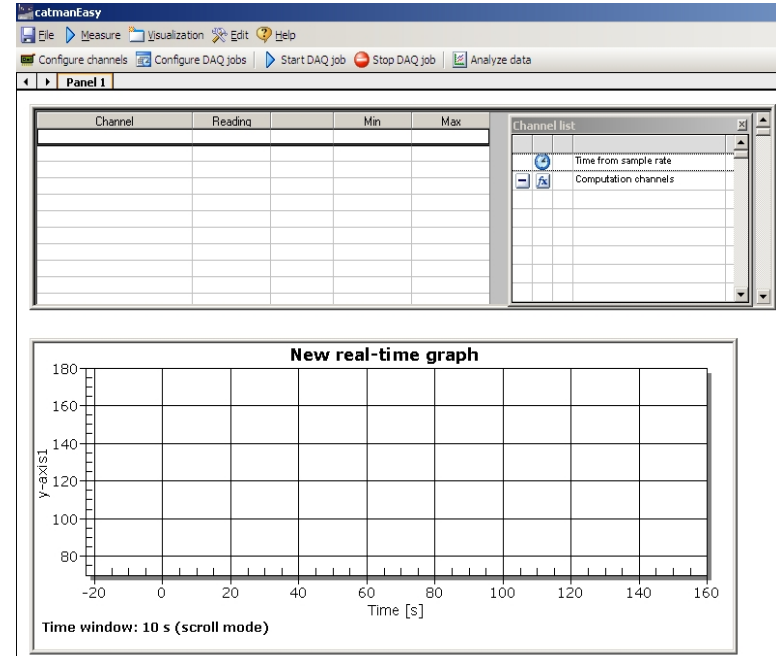

Figure 10: Selecting the channel

In the case of transducers calibration with weights (calibrated weights), it is necessary to calculate the theoretical deflections (equations 1-5) at the free end of the spring. For each type of lamellar spring, a loading range corresponding to maintaining a linear characteristic was established. In this way, the characteristic of each transducer can be drawn, which will be used in the experimental determinations. 


\begin{tabular}{|c|c|c|}
\hline \multicolumn{3}{|c|}{$\begin{array}{l}\text { Microsoft Excel-Arc_trapezoidal_Greutate10gr_CATMAN.xls } \\
\text { 중 Eile Ed Edit Yiew Insert Format Iools Data Window }\end{array}$} \\
\hline \multirow{2}{*}{\multicolumn{3}{|c|}{ 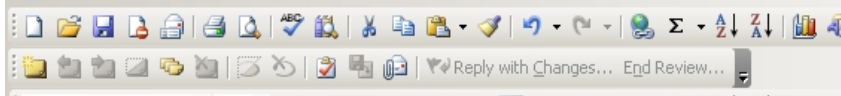 }} \\
\hline & & \\
\hline \multirow[t]{3}{*}{ Aria } & - $10 \cdot \mathbf{B} \quad \boldsymbol{I} \underline{\mathbf{U}}$ & 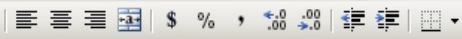 \\
\hline & $\mathrm{C} 26$ & \\
\hline & A & $\mathrm{B}$ \\
\hline 1 & File comment: & \\
\hline 2 & Time - default sample rate & Spider8_ $1 \mathrm{CHO}$ \\
\hline 3 & s & $\mu \mathrm{m} / \mathrm{m}$ \\
\hline 4 & 13.01.10 17:52:15 & 13.01.10 17:52:15 \\
\hline 5 & $20.00 \mathrm{~ms}(50 \mathrm{~Hz})$ & $20.00 \mathrm{~ms}(50 \mathrm{~Hz})$ \\
\hline 6 & Hardware channel:-12851 & Hardware channel:0 \\
\hline 7 & Serial No. (Electronics / CP): N.A. & Serial No. (Electronics / CP): N.A. \\
\hline 8 & Sensor: & Sensor: SG full bridge 350 Ohms \\
\hline 9 & Sensor T-ID: & Sensor T-ID: DMS_4_350 \\
\hline 10 & Amplifier typeUnknown & Amplifier typeSR 55 Carrier frequency + Counter \\
\hline 11 & Connector plate: N.A. & Connector plate: N.A. \\
\hline 12 & Transducer type:Unknown & Transducer type:Full bridge \\
\hline 13 & Measuring range:N.A. & Measuring range: $3 \mathrm{mVN}$ \\
\hline 14 & & \\
\hline 15 & Native unit & Native unitm $V N$ \\
\hline 16 & Engineering unit: & Engineering unit: \\
\hline 17 & Nominal range: $-4.316021 \mathrm{E}+08$ & Nominal range: $-4.316021 \mathrm{E}+08$ \\
\hline 18 & catman Scaling:External hardware & catman Scaling: Strain gage wiring \\
\hline 19 & Excitation:Unknown & Gage factor:2 \\
\hline 20 & Filter characteristics:Unknown & Bridge factor: 4 \\
\hline 21 & Filter frequency:Unknown $\mathrm{Hz}$ & Shunt correction factor1 \\
\hline 22 & Zero balancing:-4.316021E+08 s & Excitation:Unknown \\
\hline 23 & Tare value $-4.316021 \mathrm{E}+08 \mathrm{~s}$ & Filter characteristics:Bessel lowpass \\
\hline 24 & Software zero: $0 \mathrm{~s}$ & Filter frequency: $5 \mathrm{~Hz}$ \\
\hline 25 & Signal measured:N.A. & Zero balancing: $0 \mu \mathrm{m} / \mathrm{m}$ \\
\hline 26 & Amplifier input:N.A. & Tare value: $0 \mu \mathrm{m} / \mathrm{m}$ \\
\hline 27 & Gage factor-431602100.00000 & Software zero: $41.28 \mu \mathrm{m} / \mathrm{m}$ \\
\hline 28 & Bridge factor-431602100.00000 & Signal measured:N.A. \\
\hline 29 & N.A. & Amplifier input:N.A. \\
\hline 30 & & Gage factor: 0.00000 \\
\hline 31 & & Rridape fartnr:П กחกחก \\
\hline
\end{tabular}

Figure 11: Generating EXCEL file

\section{Gluing Technology for Strain Gauges}

A strain gauge is a device for measuring the tension of an object, being of different geometric shapes, nominal resistances, and the most common type of strain gauge consists of a flexible insulator that supports a metal foil.

Preparation of strain gauge. Prior preparation of the strain gauge and soldering terminals is also required. The solder terminals are delivered in the form of a strip, with 10 terminals on one strip (figure 12).

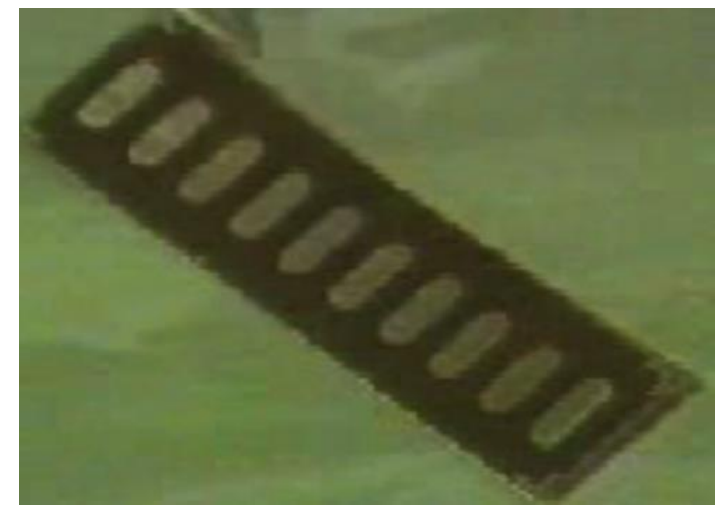

Figure 12: Strain gauges terminals strip

They must be cut 2 by 2 , requiring a distance of at least $0.5 \mathrm{~mm}$ between the solder portion of the wire and the edge of the terminal, for insulation, so that the cut is made exactly between two connecting terminals (figure 13). The surface of the terminal resulting from the cutting must be cleaned of oxides with a glass fibber brush. To avoid contamination of terminals and marks, all operations will always be performed on a clean surface, preferably paper can be changed whenever needed. The surfaces on which the strain gauges are to be glued must be perfectly cleaned and dried using, RMS1, an ecological cleaning solvent with a high power of removing grease and dirt. To keep the solvent pure, it will never be used directly from the container, a small amount needed to clean the terminals and strain gauges to be used will be poured into another vessel. The solvent container should be handled with great care because it is based on technical alcohol and it is forbidden to inhale vapours or work with open fire as it is extremely flammable.

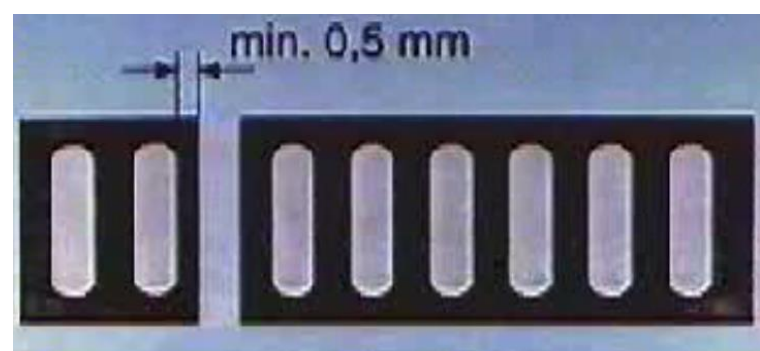

Figure 13: Cut between two connecting terminals

Immediately after the final cleaning and degreasing of the lamellar spring, the strain gauge and the terminal will be assembled, which were 
temporarily glued with an adhesive tape, on a plastic foil, in the previous steps, now cutting from the plastic foil remaining a part containing the adhesive tape (figure 14) for easier application on the surface of the lamellar spring.

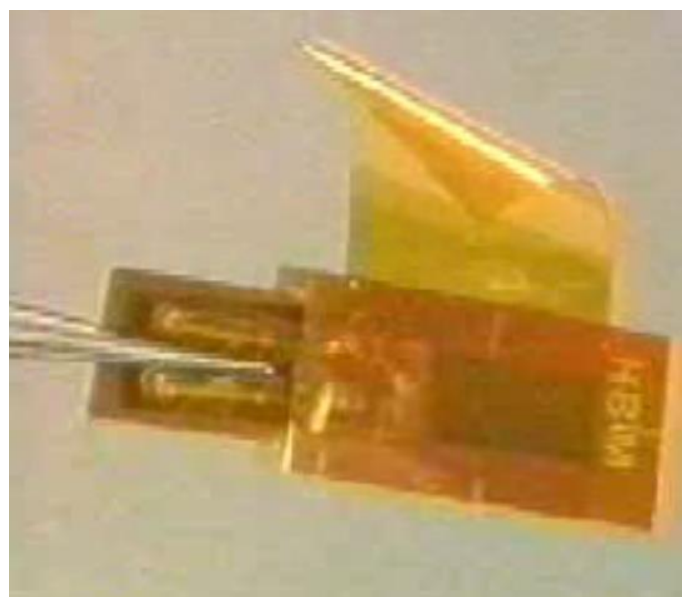

Figure 14: Strain gauge and terminals on a plastic foil

Fixing connections (wires) and electrical check. To fix the wires to the lamellar spring and to avoid loosening the electrical connections, a twocomponent, very resistant adhesive was used, which fills the gaps, BISON EPOXY METAL, recommended for metal and plastic objects. Using two gluing components, they must first be mixed in order to obtain the gluing paste and be applied over the threads (see figure 15). It takes 24 hours for the adhesive to harden completely.

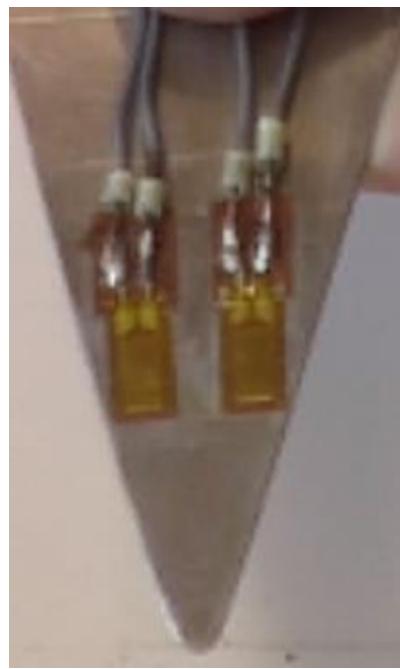

Figure 15: The strain gauges glued on the leaf spring

\section{Experimental Results}

An example of the experimental determinations, obtained in the case of solution A, is presented below for the trapezoidal lamellar spring. Table 1 specifies the values of the applied weights and the values measured by the Wheatstone bridge.
Table 1. Mass and Spider Indication

\begin{tabular}{|c|c|}
\hline $\begin{array}{c}\text { Mass } \\
{[\mathbf{g}]}\end{array}$ & $\begin{array}{c}\text { Spider Indication } \\
{[\boldsymbol{\mu m} / \mathbf{m}]}\end{array}$ \\
\hline 0 & 0 \\
\hline 10 & 221,10 \\
\hline 20 & 406,02 \\
\hline 30 & 590,88 \\
\hline 70 & 1368,24 \\
\hline 100 & 1669,32 \\
\hline
\end{tabular}

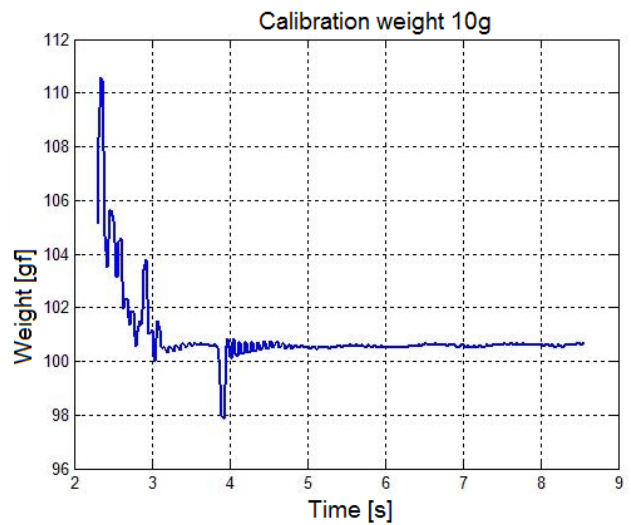

Figure 12: Trapezoidal spring calibration $10 \mathrm{~g}$

Corresponding to the values shown in table 1 for trapezoidal spring the results of spring calibration are presented in figures 12-15.

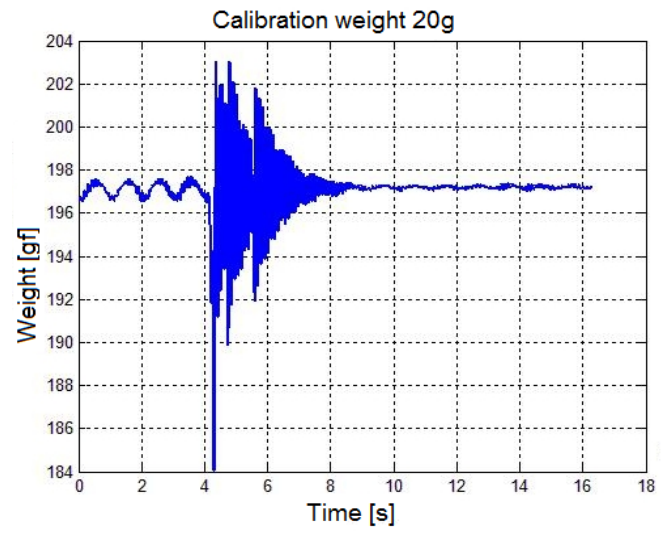

Figure 13: Trapezoidal spring calibration $20 \mathrm{~g}$

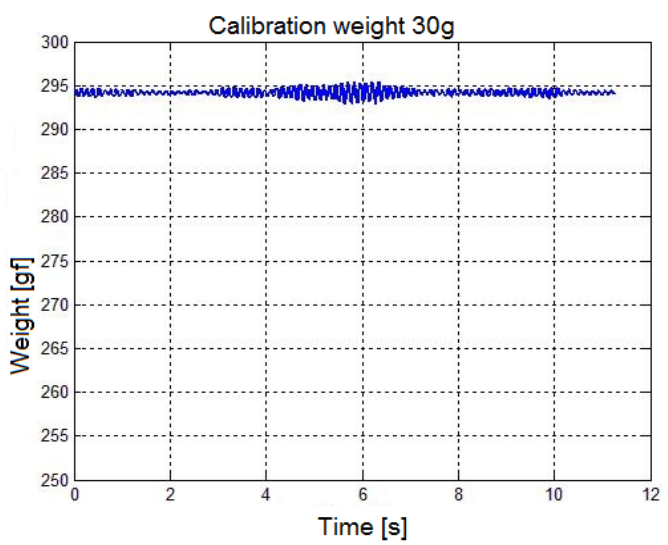

Figure 14: Trapezoidal spring calibration $30 \mathrm{~g}$ 


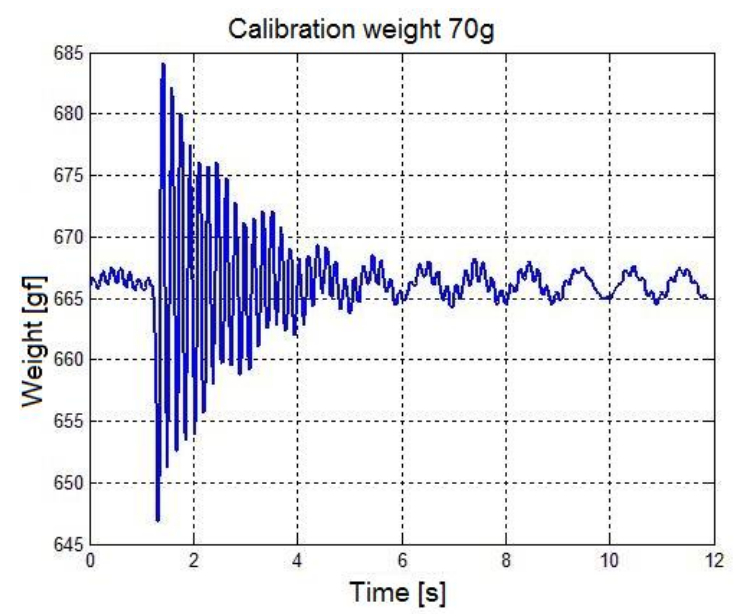

Figure 15: Trapezoidal spring calibration $70 \mathrm{~g}$

From the above, it is observed that the force transducers subjected to calibration were tested within both variants $A$ and $B$. The authors established a correspondence between the pressing force of the lamellar springs, with the help of the experimental stand from variant $A$ and the indication of the Spider 8 unit, with the help of stand from variant B. The obtained results were represented graphically in figure 16.

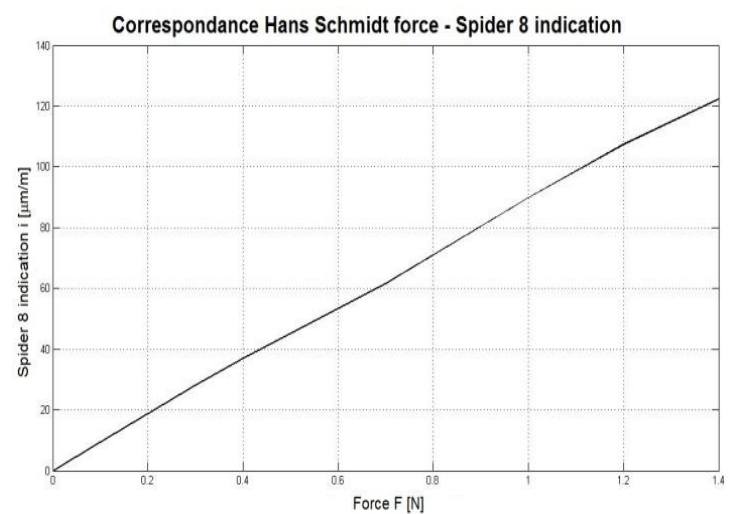

Figure 16: Correspondence Force - Spider indication

In the subsequent figures there are presented the graphical representation of lamellar springs characteristics. For each experimental determination a linear shape of characteristic was found, using least squares method. Curve Fitting Toolbox software, from Matlab, uses the linear least-squares method to fit a linear model to data. A linear model is defined as an equation that is linear in the coefficients. In figure 17 is presented characteristic for the rectangular spring with two strain gauges, mounted in half bridge.

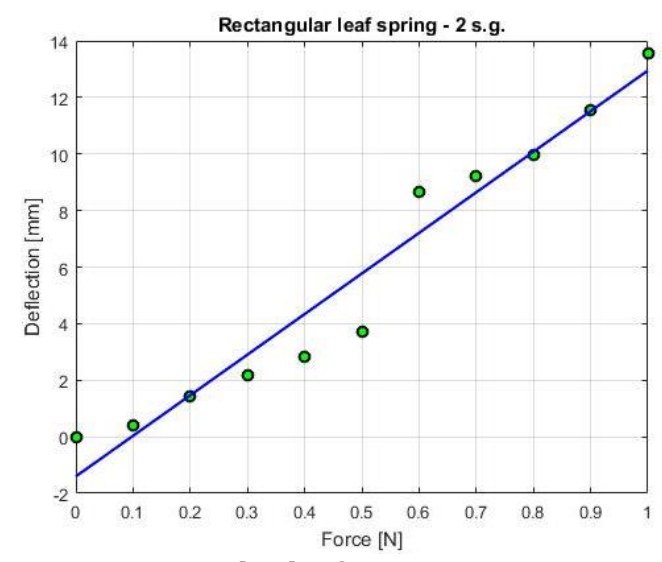

Figure 17: Rectangular leaf spring - 2 strain gauges

In figure 18 is shown the characteristic of triangular leaf spring equipped with four strain gauges. For characteristics shown in figures 19 and 20 one can observe that the regression equations are printed on the graphical illustration. This equations could be used after the calibration process is closed and the transducers are used in industrial environment.

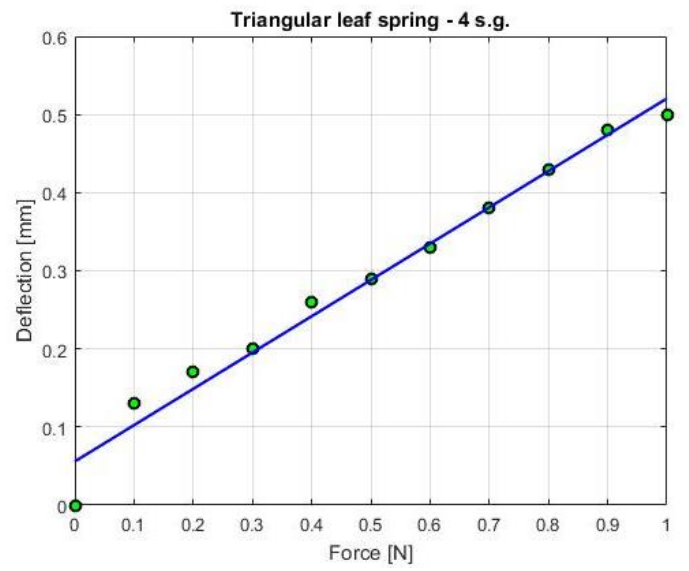

Figure 18: Triangular leaf spring - 4 strain gauges

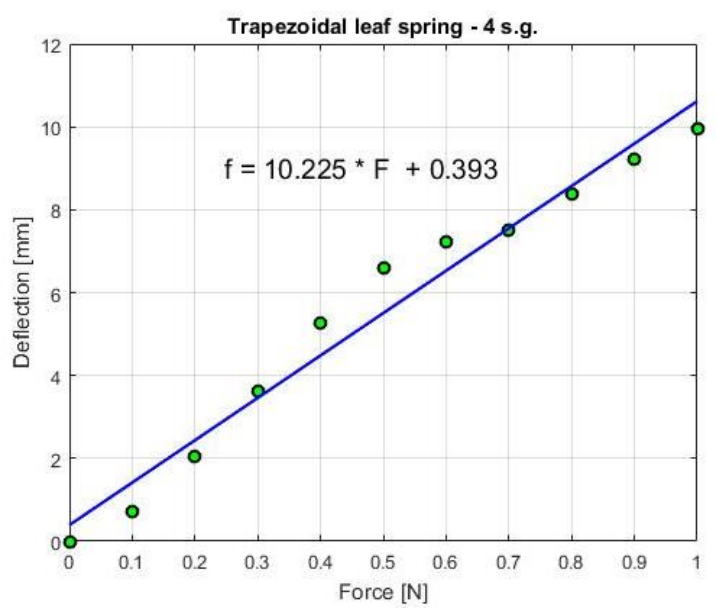

Figure 19: Trapezoidal leaf spring - 4 strain gauges 


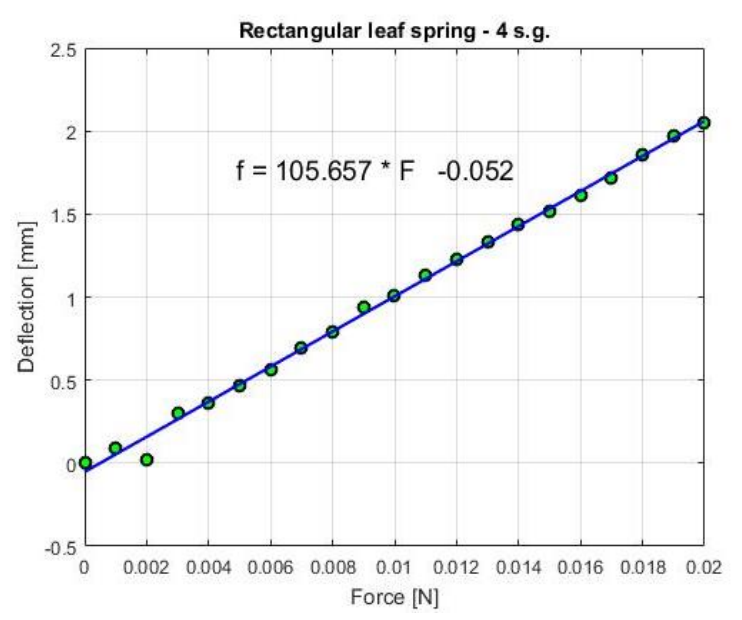

Figure 20: Rectangular leaf spring - 4 strain gauges

The accuracy of the recorded results is shown by the residue value (coefficient of determination) close to $1(\mathrm{R}=0.993654)$. This value was extracted from the statistical analysis of the regression equation $\mathrm{f}=$ $40,225 \cdot F+0.393$, shown in figure 19 , where $\mathrm{f}$ is the spring deflection and $\mathrm{F}$ is the acting force. Also for rectangular leaf spring the regression equation is: $\mathrm{f}=$ $105,657 \cdot \mathrm{F}-0,052$, presented in figure 20 .

\section{Conclusions}

1. Calibration of force transducers was performed for different forms of lamellar springs: rectangular, triangular, trapezoidal. The best behaviour in terms of the characteristic of transducers is the triangularshaped lamellar spring transducer.

2. Two materials were considered: steel and bronze. Depending on the force field to be measured, one material or another is chosen.
3. For calibration, two methods were used generically called in the project solution A (using calibrated weights) and solution B that uses an experimental setup that can be determined in addition to the force and the spring deflection at the point of application of the force.

4. Calibration results are the characteristics of transducers that make it possible to use transducers in industrial applications.

\section{References}

[1] Bishop, R.,: The Mechatronics Handbook, The University of Texas at Austin, Austin , Texas , CRC Press, 2002

[2] Demian, T., Palade, D., Curita, I.: Elastic elements in precision engineering instruments. Printed by Editor Tehnica, Bucharest, Romania, 1994. (in Romanian

[3] Rizescu, C.I.: Instruments and mechanisms for Precision engineering, Part I. Printed by Editor Printech, Bucharest, Romania, 2013. (in Romanian)

[4] Rizescu, C., Besnea, D., Rizescu D., Moraru, E., Constantin, V.,: Mechanical Analysis of Leaf Springs Realized by Additive Technologies, J. Trojanowska et al. (Eds.): Advances in Manufacturing II - Volume 1, LNME, pp. 307-318, 2019

[5] Ştefănescu, D., Farcasiu, T., Toader, A.,: Strain Gauge Force Transducer and Virtual Instrumentation Used in a Measurement System for Retention Forces of Palatal Plates or Removable Dentures. IEEE Sensors Journal. 12. 2968 - 2973, 2012

[6] http://www.freepatentsonline.com/2002007084 $0 . p d f$

[7] http://spectromas.ro/wpcontent/uploads/2018/02/Brosura-catman.pdf

[8] https://www.hbm.com/fileadmin/mediapool/hb mdoc/technical/B05403.pdf 